\title{
Aislamiento e identificación de microorganismos ambientales del museo Tumbas Reales de Sipán
}

\section{Isolation and identification of the environmental microorganism of the Tumbas Reales de Sipán museum}

\author{
Rocío Farro-Barbaran ; Willy Mauricio Ramos-Iturregui ; Sebastián Iglesias-Osores ${ }^{3 *}$; Carmen Carreño-Farfán ${ }^{4}$
}

\begin{abstract}
'Bióloga. Universidad Nacional Pedro Ruiz Gallo, Facultad de Ciencias Biológicas. Lambayeque, Perú; e-mail: rociofarrob@gmail.com; (D) https://orcid.org/0000-
\end{abstract} 0002-0767-0491

²Biólogo. Universidad Nacional Pedro Ruiz Gallo, Facultad de Ciencias Biológicas. Lambayeque, Perú; e-mail: willy_rit@hotmail.com; (D) https://orcid.org/00000001-7962-9028

${ }^{3}$ Biólogo. Universidad Nacional Pedro Ruiz Gallo, Facultad de Ciencias Biológicas. Lambayeque, Perú; e-mail: sebasiglo@gmail.com; (D) https://orcid.org/00000002-4984-4656

${ }^{4}$ Bióloga. Universidad Nacional Pedro Ruiz Gallo, Facultad de Ciencias Biológicas. Lambayeque, Perú; e-mail: ccarreno@unprg.edu.pe; (D) https://orcid.org/00000003-0238-2666

*autor de correspondencia: siglesias@unprg.edu.pe

Cómo citar: Farro-Barbaran, R.; Ramos-Iturregui, W.M.; Iglesias-Osores, S.; Carreño-Farfán, C. 2021. Aislamiento e identificación de microrganismos ambientales del museo Tumbas Reales de Sipán. Rev. U.D.C.A Act. \& Div. Cient. 24(2):e1533 http://doi.org/10.31910/ rudca.v24.n2.2021.1533

Artículo de acceso abierto publicado por Revista U.D.C.A Actualidad \& Divulgación Científica, bajo una Licencia Creative Commons CC BY-NC 4.0

Publicación oficial de la Universidad de Ciencias Aplicadas y Ambientales U.D.C.A, Institución de Educación Superior Acreditada de Alta Calidad por el Ministerio de Educación Nacional.

Recibido: abril 26 de 2020

Aceptado: julio 2 de 2021

Editado por: Ingeborg Zenner de Polanía

\section{RESUMEN}

Las bacterias y los hongos son un riesgo potencial para el material arqueológico y trabajadores de los museos en Lambayeque, Perú. Con el objetivo de cuantificar la microbiología ambiental aislada del museo Tumbas Reales de Sipán, se muestrearon cuatro almacenes, con Agar Nutritivo y Agar Papa Dextrosa, incubándose a $30^{\circ} \mathrm{C}$, en aerobiosis, hasta por 7 días, para bacterias y, hasta por 10 días, para hongos. Se cuantificaron bacterias con un máximo de $2,7 \times 10^{4} \mathrm{UFC}$ $\mathrm{cm}^{-2}$, en las superficies de pisos y paredes; $1,4 \times 10^{3} \mathrm{UFC} \mathrm{m}^{-3}$, en el aire y hongos filamentosos, con un máximo de $7,5 \times 104 \mathrm{UFC} \mathrm{cm}^{-2}$, en las superficies y $9,1 \times 10^{4} \mathrm{UFC} \mathrm{m}^{-3}$, en el aire. Se aislaron e identificaron los géneros de bacterias: Bacillus, Micrococcus, Acinetobacter, Nocardia, Streptococcus, Staphylococcus y Streptomyces y los géneros de hongos filamentosos: Aspergillus, Cladosporium, Circinella, Syncephalastrum, Penicillium, Alternaria, Staphylotrichum, Cercospora, Rhizopus, Cunninghamella, Chrysosporium, Nigrospora, Stachybotrys, Gliocladium y Verticillium.

Palabras claves: Museo arqueológico; Biodeterioro; Material arqueológico; Manejo de museos; Curaduría. 


\section{ABSTRACT}

Bacteria and fungi are a potential risk to archaeological material and museum workers in Lambayeque, Peru. In order to quantify the isolated environmental microbiology of the Tumbas Reales de Sipán museum, four warehouses were sampled with Nutritive Agar and Papa Dextrose Agar, incubated at $30^{\circ} \mathrm{C}$ in aerobiosis for up to 7 days for bacteria and up to 10 days for fungi. Bacteria were quantified with a maximum of $2.7 \times 10^{4} \mathrm{CFU} \mathrm{\textrm {cm } ^ { - 2 }}$ on the floor and wall surfaces, $1.4 \times 103 \mathrm{CFU} \mathrm{m}-3$ in the air and filamentous fungi with a maximum of $7.5 \times 10^{4} \mathrm{CFU} \mathrm{cm}{ }^{-2}$ on the surfaces and $9.1 \times 10^{4} \mathrm{CFU}$ $\mathrm{m}^{-3}$ in the air. Bacterial genera were isolated and identified: Bacillus, Micrococcus, Acinetobacter, Nocardia, Streptococcus, Staphylococcus and Streptomyces and the filamentous fungal genera: Aspergillus, Cladosporium, Circinella, Syncephalastrum, Penicillium, Cyrryspunrichum, Cyrrysopositive, Cyrrysylopola Rushingum, Cyrrysophyllizum, Nigrospora, Stachybotrys, Gliocladium and Verticillium.

Keywords: Archeological Museum; Biodeterioration; Archeological Material; Museum management; Curatorship.

\section{INTRODUCCIÓN}

Las culturas prehispánicas han confeccionado complejos y edificios monumentales durante siglos, así como material cerámico y textil. La región de la costa norte de Perú, se ha caracterizado por sus impresionantes cerámicas y orfebrería (Shimada et al. 2003). En 1987-1990, se recuperó un espectacular tesoro de artefactos ornamentales y ceremoniales de oro y plata de las tumbas reales no saqueadas de Sipán, Perú (que data de 50-300 d.c.). Estos objetos dan evidencia de la artesanía sobresaliente de los orfebres Moche y reflejan las diversas técnicas elaboradas de metalurgia disponibles, en ese momento (Hörz \& Kallfass, 2000). Hoy en día, estos artefactos están almacenados en condiciones ambientales no óptimas para climas tropicales, que muestran una colonización y deterioro visibles por comunidades microbianas. Las actividades de las comunidades microbianas en patrimonio cultural son causas importantes de daños, a través de procesos químicos o mecánicos (Ciferri, 2002; Warscheid \& Braams, 2000). Este tipo de daño por microbiota, se conoce como biodeterioro, que se refiere a cualquier actividad biológica que afecta la apariencia e integridad de los materiales (Sterflinger \& Piñar, 2013). El término "biodeterioro", también se puede definir como la alteración no deseada de varios materiales, causada por pequeños organismos vivos, como insectos (Kakakhel et al. 2019).

La presencia y actividad de arqueas, bacterias, algas, líquenes, hongos, a veces animales y plantas superiores, a menudo, causan biodeterioro de reliquias de cerámica, resto óseos y metales, por lo tanto, son amenazas importantes para la preservación a largo plazo, de este valioso patrimonio cultural (Kakakhel et al. 2019). Los hongos juegan roles positivos y negativos en nuestra vida diaria. Son patógenos que sintetizan sustancias corrosivas y micotoxinas, que tienen el potencial de causar biodeterioro materiales, como piedra y hormigón (Meng et al. 2016; 2017) y también en materiales poliméricos (Gu et al. 1998, Gu, 2003). El daño de los objetos del patrimonio cultural es un proceso causado por los procesos químicos y físicos, propios del metabolismo de los organismos involucrados (Kakakhel et al. 2019). El crecimiento microbiano en la superficie de los materiales puede causar el agrietamiento y el desplazamiento de los materiales de construcción, lo que resulta en el debilitamiento y la destrucción completa de los monumentos (Farooq et al. 2015; Liu et al. 2018). El biodeterioro, se ha discutido ampliamente, pero sus impactos negativos se han subestimado, debido a las pocas investigaciones sobre los mecanismos involucrados en el pasado (Kakakhel et al. 2019). Alguna vez, se creyó que los procesos químicos son los principales factores responsables de la descomposición, pero ahora las percepciones han cambiado y se ha aceptado, en general, que las bacterias, las arqueas y los hongos causan una seria destrucción al patrimonio cultural, como las momias, los libros y las pinturas, a través de su actividad enzimática, procesos metabólicos y corrosión/daño (Sterflinger \& Piñar, 2013). El objetivo general fue identificar los microrganismos ambientales aislados de los almacenes del museo Tumbas Reales de Sipán, en Lambayeque, Perú.

\section{MATERIALES Y MÉTODOS}

El trabajo de investigación fue descriptivo de corte transversal, se analizaron 54 unidades de muestreo de los almacenes del museo Tumbas Reales Señor de Sipán, durante agosto-octubre de 2015. El muestreo, se realizó en los almacenes del museo Tumbas Reales Señor de Sipán, en la provincia de Lambayeque, ubicada en la región Lambayeque, a $5^{\circ} 28^{\prime} 36^{\prime \prime}$ y $7^{\circ}$ 14'37" latitud Sur, 7941'30" y 80³7'23" de longitud Oeste y 18 $\mathrm{m}$ s.n.m. Los almacenes donde se colectaron las muestras fueron Ventarrón, El Triunfo, Santa Rosa y Sipán. En los tres primeros, se guardaban restos orgánicos y cerámicas y, en el cuarto, se almacén cerámicas y objetos metálicos. En cada almacén, las muestras se obtuvieron en la superficie del piso, superficie de pared, aire del ambiente y aire de cajas conteniendo material arqueológico, tomando en cuenta una zona expuesta, cerca de la puerta o ventana y una zona protegida (Figura 1, 2 y 3).

En la superficie de pisos y de paredes, se delimitaron dos áreas de $1 \mathrm{~m}^{2}$, en las zonas expuesta y protegida, donde se colocaron seis "marcos" de cuadrados de cartulina, que delimitaron áreas de $5 \times 5 \mathrm{~cm}$ y una superficie de $25 \mathrm{~cm}^{2}$ (Figura $1 \mathrm{a}$ y $1 \mathrm{~b}$ ).

Estos marcos fueron esterilizados en horno $\left(180{ }^{\circ} \mathrm{C} \times 20^{\prime}\right)$, se ubicaron en el área delimitada: cuatro en las esquinas y dos en el centro y en el interior, se tomaron las muestras con hisopos estériles $\left(180{ }^{\circ} \mathrm{C}\right.$ x $\left.2 \mathrm{~h}\right)$ y humedecidos con una solución de cloruro de sodio $(\mathrm{NaCl} 0,85 \% \mathrm{p} / \mathrm{v})$, más Tween 80. La superficie muestreada, se frotó con el hisopo en sentido horizontal, vertical y diagonal; luego, los hisopos se depositaron en tubos con la misma solución, para el posterior aislamiento en Agar nutritivo, con antibiótico Cicloheximida y Agar Papa Dextrosa con Cloranfenicol.

El muestreo de aire en los almacenes, se realizó en seis áreas delimitadas por un tablero de $50 \times 50 \mathrm{~cm}$, sostenido por un soporte de cartón prensado, a una altura de 1,20 cm. Los lugares 


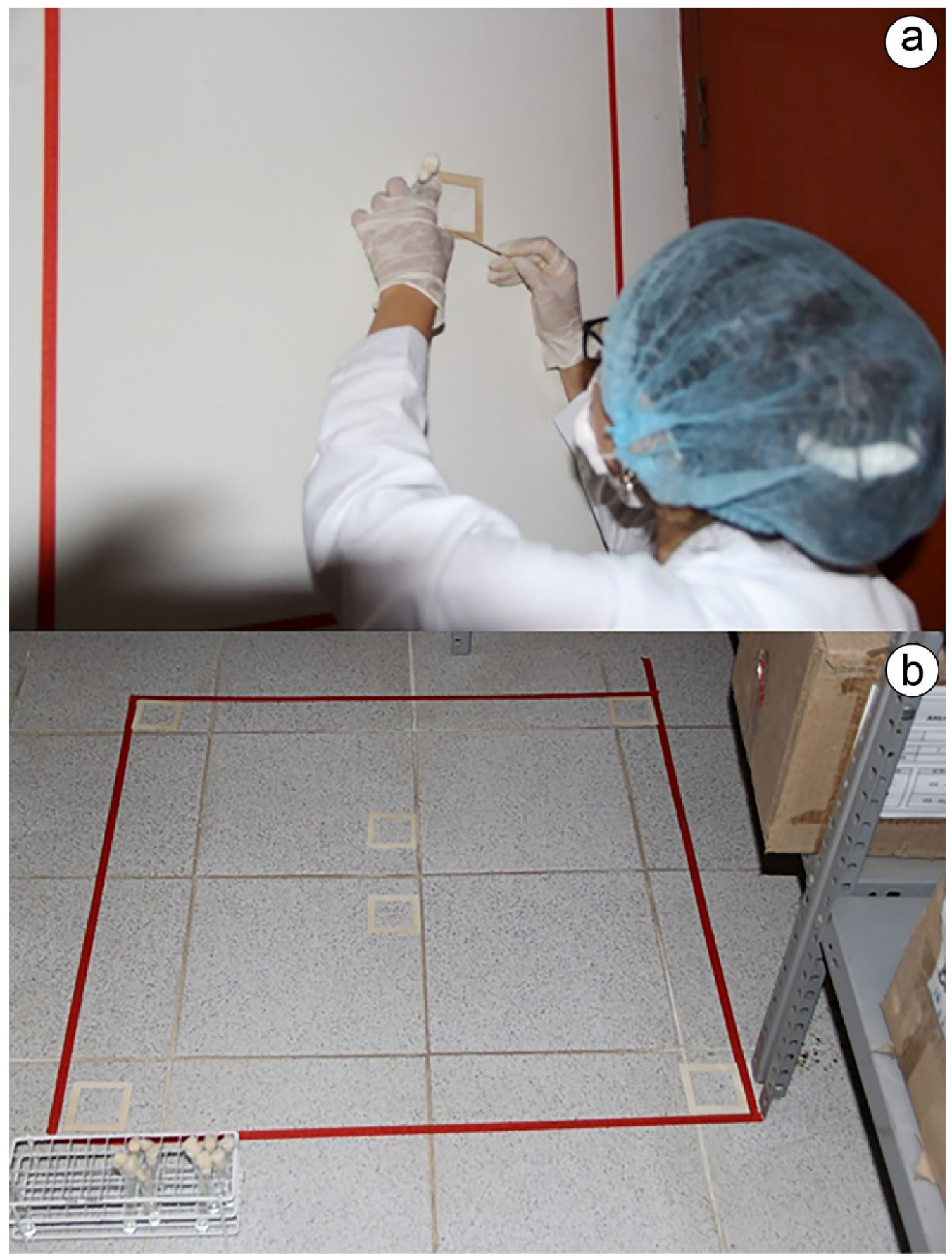

Figura 1. Ubicación de marco de cuadrado para el muestreo. a. en la pared; b. en el suelo.

seleccionados correspondieron a tres zonas protegidas (no hubo corrientes de aire) y tres expuestas (cerca de ventanas y puertas con corrientes de aire), de los almacenes. Según la técnica de sedimentación por gravedad sobre el tablero, se colocaron en las esquinas (4) y en el centro (2) placas de Petri, con Agar Nutritivofluconazol (tres placas), Agar Sangre-antimicótico (dos placas) y Agar Papa dextrosa (tres placas) y se mantuvieron abiertas durante 15 minutos (López-Aranda et al. 2020) (Figura 2).

En los estantes de los ambientes muestreados, se seleccionaron dos cajas de almacenamiento: en las zonas "protegida" y "expuesta", se retiraron las tapas y, en su interior, se colocaron las placas de Petri abiertas, con Agar Nutritivo (tres placas) y Agar Papa Dextrosa (tres placas). Las cajas se taparon, cada 5 minutos, las paredes y la tapa de las cajas, se golpearon durante medio minutos y después de 15 minutos, se retiraron las placas de Petri. Los tubos con las muestras de superficie y las placas de Petri con las muestras de aire, se depositaron en la caja térmica $\left(10 \pm 1^{\circ} \mathrm{C}\right)$ y se llevaron al laboratorio de Microbiología y Parasitología, para el aislamiento de bacterias y hongos (Figura 3). 


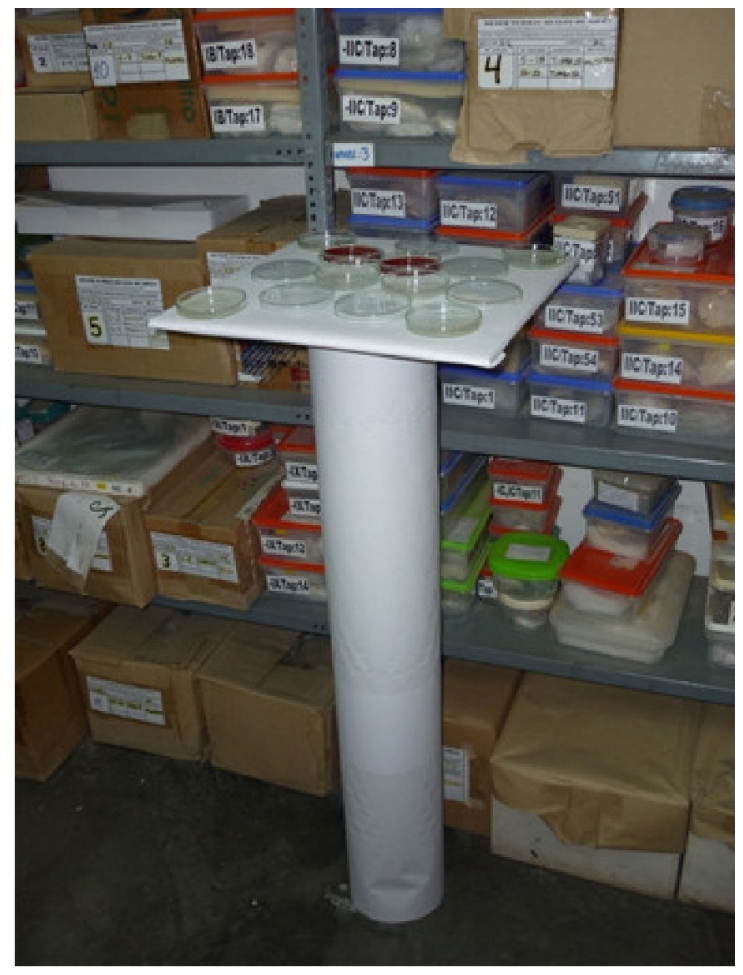

Figura 2. Muestreo de aire en almacén.

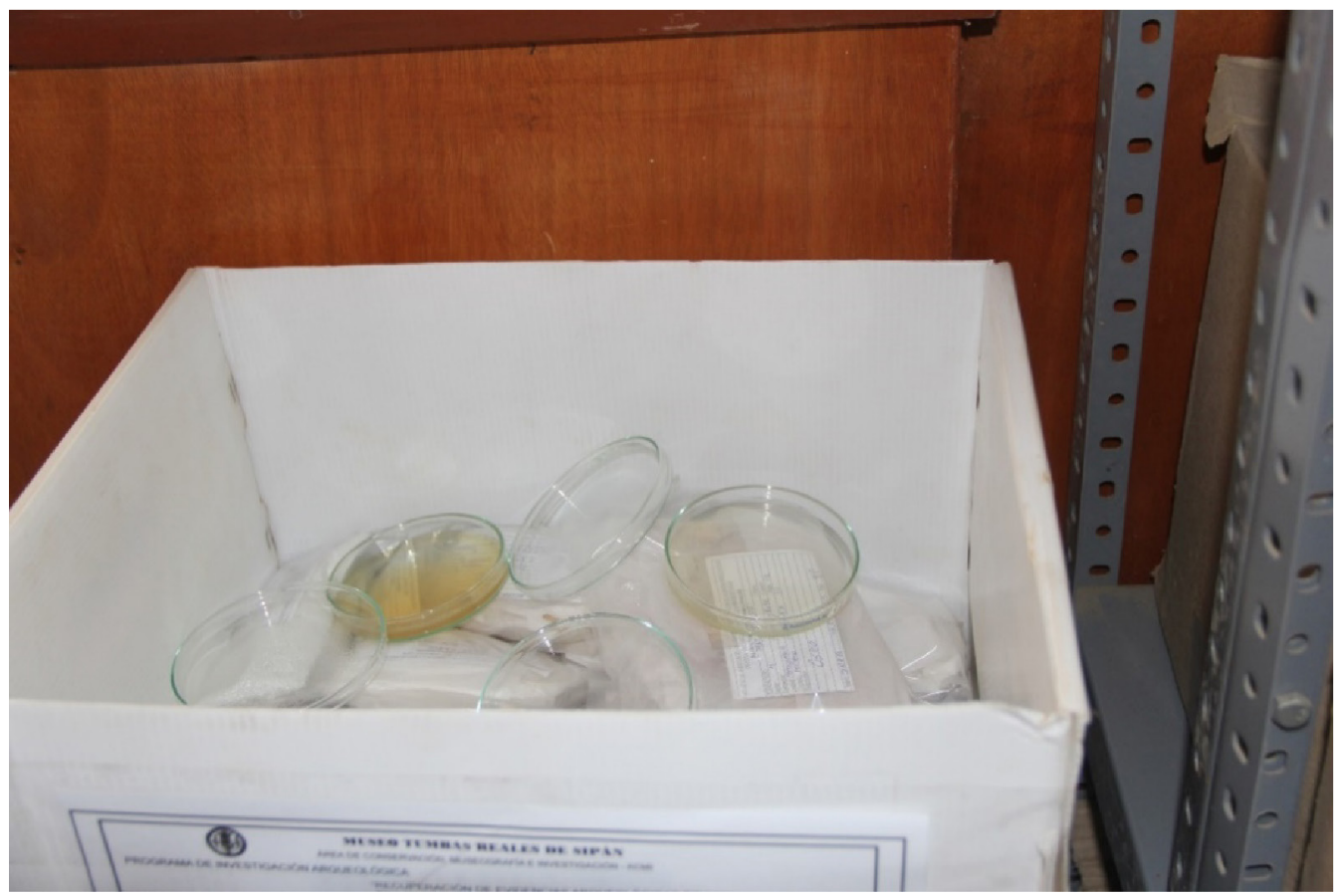

Figura 3. Placas de Petri con medios de cultivo abiertas en caja de almacenamiento.

Las muestras de superficies de pisos y de paredes colectadas con hisopos fueron sembradas en placas de Petri con Agar Nutritivofluconazol, para cuantificar bacterias y Agar Papa Dextrosaantibiótico, para cuantificar hongos. La incubación, se realizó a $30^{\circ} \mathrm{C}$, en aerobiosis, hasta por 7 días, para bacterias y 10 días, para hongos. El número de unidades formadoras de colonias por metro cúbico de aire $\left(\mathrm{UFCm}^{-3}\right)$ o metro cuadrado de superficie $\left(\mathrm{UFCm}^{-2}\right)$, se calculó según la ecuación 1 .

$\mathrm{N}=5 \mathrm{a} \times 10^{4}(\mathrm{bt})^{-1}$ 
Donde: $\mathrm{N}=\mathrm{UFCm}^{-3}$ o $\mathrm{UFCm}^{-2}$; $\mathrm{a}=$ número de colonias por placa de Petri; b (para $\left.\mathrm{m}^{-2}\right)=$ área (lado2) del muestreador $\left(\mathrm{cm}^{2}\right)$; $\mathrm{b}\left(\right.$ para $\left.\mathrm{m}^{-3}\right)=$ área $\left(\pi \mathrm{R}^{2}\right)$ de la placa de Petri $\left(\mathrm{cm}^{2}\right) ; \mathrm{t}=$ tiempo de exposición.

Las colonias de bacterias y los hongos fueron agrupados, según su morfología y cada morfotipo, se aisló por duplicado, en viales con Agar Nutritivo y Agar Papa Dextrosa.

En la identificación de las bacterias, se determinaron las características macroscópicas de las colonias desarrolladas en agar nutritivo a $37^{\circ} \mathrm{C}$, durante 3 días. Para la identificación, a nivel de género, se realizaron tinciones de Gram y de Ziehl-Neelsen y las pruebas de catalasa, motilidad, acidez a partir de carbohidratos, hidrólisis del almidón y gelatina, tolerancia a $\mathrm{NaCl}$, hidrólisis de arginina, reducción de nitratos, prueba de Vogues Proskauer.

Para la identificación de hongos, se usaron las características macroscópicas de las colonias desarrolladas en agar papa dextrosa a $30^{\circ} \mathrm{C}$, hasta por 10 días, para llegar a género. A continuación, con la técnica de "impresión con cinta adhesiva transparente" (Labarca et al. 2006), sobre cada colonia de hongo, se depositó un fragmento de cinta adhesiva de $6 \mathrm{~cm}$ de longitud y luego se llevó a una lámina portaobjetos, conteniendo una gota de azul de lactofenol; se presionó de manera sucesiva y se observó con objetivo de 40x, identificándose las características microscópicas del micelio vegetativo y las estructuras reproductivas (Barnett \& Hunter, 1998).

Los datos obtenidos fueron ordenados y expresados en tablas y figuras, que permitieron visualizar y analizar las bacterias y los hongos de riesgo potencial, para el material arqueológico y trabajadores del museo. Los datos fueron procesados utilizando los programas Microsoft Office Word 2013 y Microsoft Office Excel 2013.

\section{RESULTADOS Y DISCUSIÓN}

Los hongos y las bacterias y el número de unidades formadoras de colonias de los microorganismos aislados en los almacenes del museo Tumbas Reales Señor de Sipán, se muestran en las tablas 1 y 2.

En las superficies y ambiente de los almacenes del museo Tumbas Reales Señor de Sipán, en Lambayeque, se cuantificaron bacterias y hongos filamentosos; en otros estudios sobre biodeterioro, también se aislaron géneros de bacterias y hongos, que colonizaban material histórico, en almacenes de museos (Grbić et al. 2013; Konsa et al. 2014). En el aire de los almacenes, se cuantificaron hasta $1,3 \times 10^{3}$ $\mathrm{UFCm}^{-3}$, superando $2,6 \times 10^{2} \mathrm{UFCm}^{-3}$, reportados por Guiamet $e t$ al. (2011). Esto quizás se deba a la manera de almacenamiento y a los materiales arqueológicos almacenados.

La variedad de partículas de diferente origen forma y tamaño suspendidas en el aire del interior y exterior de los ambientes constituye el aerosol atmosférico. Las instalaciones históricas, como iglesias, criptas, bibliotecas y museos, son cruciales para preservar el patrimonio cultural, pero, al mismo tiempo, se visitan con frecuencia objetos turísticos y entornos de trabajo (Chmiel et al. 2019).

Se considera que la mayoría de las esporas de hongos se encuentran al aire libre, por lo que podrían ingresar a la mayoría de los locales examinados con el aire exterior o en la ropa de las personas. Por otro lado, los principales depósitos interiores de aerosoles bacterianos son la piel de humanos y animales, por lo tanto, los microorganismos predominantes en el aire atmosférico serían hongos, mientras que las bacterias prevalecerían en interiores (Cox \& Wathes, 1995; Karbowska-Berent et al. 2011). Cuando se excluye la infiltración del aire exterior, el aumento del número de partículas fúngicas en el aire de bibliotecas, archivos y museos puede resultar de la dispersión de algunas fuentes internas, por ejemplo, colecciones contaminadas, papel tapiz o pintura (KarbowskaBerent et al. 2011).

En la superficie de pisos y paredes, se cuantificaron hasta $2,7 \times 10^{4}$ $\mathrm{UFCcm}^{-2}$, de bacterias, valor inferior a $7,1 \times 10^{5} \mathrm{UFCcm}^{-2}$, reportado por Guiamet et al. (2011), en la superficie de mapas y fotografías de un museo. Al respecto, una diversidad de bacterias se ha cuantificado y aislado en diferentes materiales arqueológicos, en fibras textiles (Eyzaguirre, 2002), momias de sarcófagos (Cavka et al. 2010), cuerpos preservados en catacumbas (Piñar et al. 2013)muscle, hair, bone, stuffing materials, clothes, and surrounding walls as well as from the indoor air. In this study, we witnessed that the different degradation phenomena observed on the variety of materials located at the Capuchin Catacombs of Palermo are biological in origin. Molecular techniques showed the dominance of halophilic species of the domains Bacteria and Archaea on the walls and as a result of salt emanating from the walls - on the mummies themselves. Nevertheless, specialized microorganisms belonging to taxa well-known for their cellulolytic and proteolytic activities were detected on clothes and stuffing material, and on skin, muscle, hair, and bone, respectively. This specialized microbiota is threatening the conservation of the mummies themselves. Additionally, sequences related to the human skin microbiome and to some pathogenic Bacteria (order Clostridiales, aire, libros y documentos de museos y archivos (Sequeira et al. 2012). Fusarium no se conoce típicamente como un género fúngico importante que degrada la madera, sino que es un hongo asociado con la basura y el suelo, que es importante para degradar los detritos de las plantas y como patógenos de plantas; sin embargo, el género, a menudo, se aísla de los materiales de madera y se sabe que posee una alta actividad lignocelulolítica (Daâssi et al. 2016; Obruca et al. 2012). El número de hongos filamentosos fue mayor en el aire que en las superficies y la superioridad numérica, se debe a la rápida dispersión de las esporas, por el movimiento de las corrientes de aire. De igual manera, Rojas et al. (2012) identificaron una mayor diversidad de géneros de hongos filamentosos en el aire, en comparación con otros objetos muestreados (18 géneros).

El número de bacterias superó al de hongos filamentosos, coincidiendo con Guiamet et al. (2011). En los almacenes investigados, se 
Tabla 1. Nombre de almacén y procedencia de muestras colectadas en museo Tumbas Reales Señor de Sipán, Lambayeque, 2015.

\begin{tabular}{|c|c|c|c|c|c|c|c|}
\hline Nombre & Procedencia & Condición & Muestras & \multicolumn{4}{|c|}{ UFC Bacterias } \\
\hline \multirow{8}{*}{ Ventarrón } & \multirow{2}{*}{$\begin{array}{l}\text { Superficie de } \\
\text { piso }\end{array}$} & Expuesta & 1 & \multicolumn{2}{|c|}{$\begin{array}{c}\text { Procedencia de } \\
\text { muestras }\end{array}$} & Protegida & Expuesta \\
\hline & & Protegida & 1 & $\begin{array}{l}\text { Superficie } \\
\text { de piso }\end{array}$ & $\left(\mathrm{UFCm}^{-2}\right)$ & $2,7 \times 10^{4}$ & $2,2 \times 10^{4}$ \\
\hline & \multirow{2}{*}{$\begin{array}{l}\text { Superficie de } \\
\text { pared }\end{array}$} & Expuesta & 1 & $\begin{array}{l}\text { Superficie } \\
\text { de pared }\end{array}$ & $\left(\mathrm{UFCm}^{-2}\right)$ & $3,4 \times 10^{3}$ & $3,7 \times 10^{3}$ \\
\hline & & Protegida & 1 & $\begin{array}{c}\text { Aire de } \\
\text { ambiente }\end{array}$ & $\left(\mathrm{UFCm}^{-3}\right)$ & $1,0 \times 10^{3}$ & $1,3 \times 10^{3}$ \\
\hline & \multirow{2}{*}{$\begin{array}{c}\text { Aire de } \\
\text { ambiente }\end{array}$} & Expuesta & 3 & $\begin{array}{c}\text { Aire de } \\
\text { caja }\end{array}$ & $\left(\mathrm{UFCm}^{-3}\right)$ & $1,4 \times 10^{3}$ & $1,1 \times 10^{3}$ \\
\hline & & Protegida & 3 & \multicolumn{4}{|c|}{ UFC Hongos filamentosos } \\
\hline & \multirow{2}{*}{ Aire de caja } & Expuesta & 1 & \multicolumn{2}{|c|}{$\begin{array}{c}\text { Procedencia de } \\
\text { muestras }\end{array}$} & Protegida & Expuesta \\
\hline & & Protegida & 1 & $\begin{array}{c}\text { Superficie } \\
\text { de piso }\end{array}$ & $\left(\mathrm{UFCm}^{-2}\right)$ & $4,9 \times 10^{4}$ & $7,5 \times 10^{4}$ \\
\hline \multirow{8}{*}{ El Triunfo } & \multirow{2}{*}{$\begin{array}{l}\text { Superficie de } \\
\text { piso }\end{array}$} & Expuesta & 1 & $\begin{array}{l}\text { Superficie } \\
\text { de pared }\end{array}$ & $\left(\mathrm{UFCm}^{-2}\right)$ & $1,1 \times 10^{4}$ & $1,2 \times 10^{4}$ \\
\hline & & Protegida & 1 & $\begin{array}{c}\text { Aire de } \\
\text { ambiente }\end{array}$ & $\left(\mathrm{UFCm}^{-3}\right)$ & $9,1 \times 10^{4}$ & $5,5 \times 10^{4}$ \\
\hline & \multirow{2}{*}{$\begin{array}{l}\text { Superficie de } \\
\text { pared }\end{array}$} & Expuesta & 1 & $\begin{array}{l}\text { Aire de } \\
\text { caja }\end{array}$ & $\left(\mathrm{UFCm}^{-3}\right)$ & $3,5 \times 10^{4}$ & $7,3 \times 10^{4}$ \\
\hline & & Protegida & 1 & & & & \\
\hline & \multirow{2}{*}{$\begin{array}{l}\text { Aire de } \\
\text { ambiente }\end{array}$} & Expuesta & 3 & & & & \\
\hline & & Protegida & 3 & & & & \\
\hline & \multirow{2}{*}{ Aire de caja } & Expuesta & 1 & & & & \\
\hline & & Protegida & 1 & & & & \\
\hline \multirow{8}{*}{$\begin{array}{r}\text { Santa } \\
\text { Rosa }\end{array}$} & \multirow{2}{*}{$\begin{array}{l}\text { Suoerficie de } \\
\text { piso }\end{array}$} & Expuesta & 1 & & & & \\
\hline & & Protegida & 1 & & & & \\
\hline & \multirow{2}{*}{$\begin{array}{c}\text { Suoerficie de } \\
\text { pared }\end{array}$} & Expuesta & 1 & & & & \\
\hline & & Protegida & 1 & & & & \\
\hline & \multirow{2}{*}{$\begin{array}{l}\text { Aire de } \\
\text { ambiente }\end{array}$} & Expuesta & 3 & & & & \\
\hline & & Protegida & 3 & & & & \\
\hline & \multirow{2}{*}{ Aire de caja } & Expuesta & 1 & & & & \\
\hline & & Protegida & 1 & & & & \\
\hline \multirow{8}{*}{ Sipán } & \multirow{2}{*}{$\begin{array}{l}\text { Suoerficie de } \\
\text { piso }\end{array}$} & Expuesta & 2 & & & & \\
\hline & & Protegida & 2 & & & & \\
\hline & \multirow{2}{*}{$\begin{array}{c}\text { Suoerficie de } \\
\text { pared }\end{array}$} & Expuesta & 2 & & & & \\
\hline & & Protegida & 2 & & & & \\
\hline & \multirow{2}{*}{$\begin{array}{l}\text { Aire de } \\
\text { ambiente }\end{array}$} & Expuesta & 3 & & & & \\
\hline & & Protegida & 3 & & & & \\
\hline & \multirow{2}{*}{ Aire de caja } & Expuesta & 2 & & & & \\
\hline & & Protegida & 2 & & & & \\
\hline \multicolumn{3}{|c|}{ TOTAL } & 54 & & & & \\
\hline
\end{tabular}


Tabla 2. Frecuencia de géneros de bacterias identificadas en los almacenes del museo Tumbas Reales Señor de Sipán, Lambayeque, 2015.

\begin{tabular}{|c|c|c|c|c|c|}
\hline \multirow[t]{2}{*}{ Género } & \multicolumn{2}{|c|}{$\begin{array}{l}\text { Frecuencia }(\%) \\
\text { en almacenes }\end{array}$} & \multirow[t]{2}{*}{ Género } & \multicolumn{2}{|c|}{$\begin{array}{c}\text { Frecuencia }(\%) \\
\text { paredes de } \\
\text { almacenes } \\
\end{array}$} \\
\hline & Protegida & Expuesta & & Protegida & Expuesta \\
\hline Bacillus & 92,5 & 96,2 & Bacillus & 100 & 100 \\
\hline Micrococcus & 66,6 & 62,9 & Micrococcus & 75,0 & 75,0 \\
\hline Acinetobacter & 37,0 & 29,6 & Acinetobacter & 33,0 & 25,0 \\
\hline Nocardia & 33,3 & 29,6 & Nocardia & 25,0 & 25,0 \\
\hline Streptococcus & 18,5 & 14,8 & Streptococcus & 8,3 & 8,3 \\
\hline Staphylococcus & 14,8 & 7,4 & Streptomyces & 16,6 & 8,3 \\
\hline Streptomyces & 11,1 & 11,1 & Staphylococcus & 8,3 & 8,3 \\
\hline \multirow[t]{2}{*}{ Género } & \multicolumn{2}{|c|}{$\begin{array}{c}\text { Frecuencia }(\%) \\
\text { en piso de } \\
\text { almacenes }\end{array}$} & \multirow[t]{2}{*}{ Género } & \multicolumn{2}{|c|}{$\begin{array}{c}\text { Frecuencia }(\%) \\
\text { en piso de } \\
\text { almacenes }\end{array}$} \\
\hline & Protegida & Expuesta & & Protegida & Expuesta \\
\hline Bacillus & 100 & 100 & Bacillus & 60 & 80 \\
\hline Micrococcus & 80 & 80 & Micrococcus & 60 & 60 \\
\hline Acinetobacter & 60 & 60 & Acinetobacter & 20 & 20 \\
\hline Nocardia & 60 & 40 & Nocardia & 20 & 20 \\
\hline Streptomyces & 40 & 40 & Streptococcus & 20 & 20 \\
\hline Streptococcus & 40 & 20 & & & \\
\hline Staphylococcus & 20 & 20 & & & \\
\hline \multirow[t]{2}{*}{ Género } & \multicolumn{2}{|c|}{$\begin{array}{c}\text { Frecuencia }(\%) \\
\text { paredes de } \\
\text { almacenes }\end{array}$} & & & \\
\hline & Protegida & Expuesta & & & \\
\hline Bacillus & 100 & 100 & & & \\
\hline Nocardia & 40 & 40 & & & \\
\hline Acinetobacter & 40 & 20 & & & \\
\hline Micrococcus & 40 & 20 & & & \\
\hline Staphylococcus & 40 & 0 & & & \\
\hline Streptococcus & 0 & 20 & & & \\
\hline
\end{tabular}

identificaron siete géneros de bacterias, entre los que Bacillus, Streptococcus, Staphylococcus, Micrococcus y Streptomyces fueron reportados por Guiamet et al. (2011), así como Acinetobacter y Nocardia. Las bacterias Gram positivas predominaron frente a las Gram negativas, similar con Guiamet et al. (2011). Los cocos Gram positivos están asociados a la actividad humana; son acarreados en la piel y membranas mucosas (Zhu et al. 2003). El género Bacillus, se identificó en todas las muestras investigadas, evidenciándose un requerimiento de mantenimiento adecuado en los ambientes de procedencia (Guiamet et al. 2011).

En cuanto a las zonas investigadas, el número promedio de hongos filamentosos fue superior en las muestras de superficie de pisos, paredes y aire de las cajas de zonas expuestas, así como también en el aire del ambiente de zonas protegidas (Tabla 1). El número promedio de bacterias fue menor que el de hongos filamentosos en las superficies de pisos y paredes y en el aire de ambientes y cajas de los almacenes, en el museo Tumbas Reales Señor de Sipán (Tabla 1).

En los almacenes investigados, se identificaron 15 géneros de hongos filamentosos, entre los que Aspergillus, Cladosporium y Penicillium fueron reportados en ambientes y material arqueológico, por Guiamet et al. (2011) y Rojas et al. (2012). 
El género Syncephalastrum fue reportado por Guiamet et al. (2011) y Rojas et al. (2012); los géneros Rhiropus y Stachybotrys, por Rojas et al. (2012); Alternaria y Nigrospora, por Rojas et al. (2012); Chrysosporium, por Cavka et al. (2010).

Los géneros Verticillium, por Piñar et al. (2013); Gliocladium también, se identificaron Cunninghamella, Circinella, Staphylotrichum y Cercospora, hongos encontrados sobre materia orgánica vegetal.
El género Aspergillus fue el más frecuente, similar con Guiamet et al. (2011) y Rojas et al. (2012). Este género de hongo filamentoso ha sido reportado en el aire en superficies de mapas y fotografías (Guiamet et al. 2011), en momias (López-Aranda et al. 2020; Cavka et al. 2010) y en ambientes interiores y exteriores de bibliotecas (Montanari et al. 2012). Asimismo, Rojas et al. (2012), en el aire y soportes de siete edificios históricos, identificaron Aspergillus, como uno de los géneros de hongos filamentosos más comunes, correspondiéndole el $34,2 \%$, de 38 especies identificadas.

Tabla 3. Frecuencia de géneros de hongos filamentosos identificados en los almacenes del museo Tumbas Reales Señor de Sipán, Lambayeque, 2015.

\begin{tabular}{|c|c|c|c|c|c|}
\hline \multirow[t]{2}{*}{ Género } & \multicolumn{2}{|c|}{$\begin{array}{l}\text { Frecuencia } \\
\text { en almacenes }\end{array}$} & \multirow[t]{2}{*}{ Género } & \multicolumn{2}{|c|}{$\begin{array}{c}\text { Frecuencia }(\%) \text { superficies } \\
\text { de paredes }\end{array}$} \\
\hline & Protegida & Expuesta & & Protegida & Expuesta \\
\hline Aspergillus & 88,8 & 75,9 & Aspergillus & 100 & 40 \\
\hline Cladosporium & 62,9 & 59,2 & Circinella & 0 & 80 \\
\hline Circinella & 25,9 & 40,7 & Cladosporium & 40 & 20 \\
\hline Syncephalastrum & 37,0 & 18,5 & Syncephalastrum & 40 & 0 \\
\hline Penicillium & 29,6 & 14,8 & Rhiropus & 40 & 0 \\
\hline Alternaria & 14,8 & 14,8 & Staphylotrichum & 0 & 20 \\
\hline Staphylotrichum & 7,4 & 14,8 & \multirow[t]{2}{*}{ Género } & \multicolumn{2}{|c|}{$\begin{array}{l}\text { Frecuencia }(\%) \\
\text { en el ambiente }\end{array}$} \\
\hline Cercospora & 7,4 & 7,4 & & Protegida & Expuesta \\
\hline Rhizopus & 14,8 & 0 & Cladosporium & 100,0 & 75,0 \\
\hline Cunninghamella & 0 & 11,1 & Aspergillus & 100,0 & 66,6 \\
\hline Chrysosporium & 0 & 7,4 & Syncephalastrum & 50,0 & 25,0 \\
\hline Nigrospora & 7,4 & 0 & Alternaria & 33,3 & 33,3 \\
\hline Stachybotrys & 0 & 7,4 & Penicillium & 33,3 & 33,3 \\
\hline Gliocladium & 3,7 & 0 & Circinella & 16,6 & 25,0 \\
\hline Verticillium & 3,7 & 0 & Cercospora & 16,6 & 16,6 \\
\hline \multirow[t]{2}{*}{ Género } & \multicolumn{2}{|c|}{$\begin{array}{c}\text { Frecuencia }(\%) \\
\text { en pisos de } \\
\text { almacenes }\end{array}$} & Cunninghamella & 0 & 16.6 \\
\hline & Protegida & Expuesta & Nigrospora & 16,6 & 0 \\
\hline Aspergillus & 100 & 100 & Género & $\begin{array}{r}\text { Frecu } \\
\text { cajas de alm }\end{array}$ & \\
\hline Circinella & 100 & 80 & & Protegida & Expuesta \\
\hline Cladosporium & 20 & 60 & Aspergillus & 40 & 40 \\
\hline Syncephalastrum & 40 & 40 & Cladosporium & 40 & 40 \\
\hline Staphylotrichum & 40 & 20 & Chrysosporium & 0 & 40 \\
\hline Penicillium & 40 & 0 & Penicillium & 40 & 0 \\
\hline Gliocladium & 20 & 0 & Stachybotrys & 0 & 40 \\
\hline Verticillium & 20 & 0 & Cunninghamella & 0 & 20 \\
\hline
\end{tabular}


En los almacenes, se aislaron e identificaron siete géneros de bacterias (Tabla 2), predominando Bacillus (94,4 \%) y Micrococcus (64,8 \%), seguido de Acinetobacter (63,3\%), Nocardia $(31,4 \%)$, Streptococcus $(16,6 \%)$, Staphylococcus $(11,1 \%)$ y Streptomyces (11,1\%). Los géneros Bacillus, Micrococcus, Nocardia y Streptococcus, se identificaron en las superficies de pisos, paredes y aire de ambientes y cajas, destacando Bacillus, que se registró en todas las muestras. A su vez, Staphylococcus, se identificó en las superficies de pisos, paredes y aire de los ambientes, así como Streptomyces, en las superficies de pisos y aire de los ambientes (Tabla 2).

En la presente investigación no se identificaron levaduras; sin embargo, López-Aranda et al. (2020) reportaron los géneros Candida y Rhodotorula, junto a hongos filamentosos, en momias, con visible deterioro. En su mayoría, los microorganismos identificados en la presente investigación han sido reportados como agentes de biodeterioro, por su actividad enzimática, con hidrólisis de la celulosa, lignina y proteína, producción de ácidos orgánicos y pigmentos (LópezAranda et al. 2020), destacando Bacillus, Streptomyces (Guiamet et al. 2011), Aspergillus, Penicillium, Cladosporium, Nigrospora, Rhizopus, Syncephalastrum (Rojas et al. 2012) y Penicillium. El biodeterioro implica alteraciones de las propiedades fisicoquímicas y mecánicas del material o soporte histórico, por acción de los organismos vivos. En este aspecto, bacterias y hongos causan un daño significativo en el material histórico, como resultado de su actividad metabólica (Farooq et al. 2015).

El género Aspergillus, seguido de Cladosporium, fueron los más frecuentes y se identificaron en las superficies de pisos, paredes y aire de ambientes y cajas de todos los almacenes. Los géneros Circinella, Syncephalastrum y Penicillium, se identificaron en las superficies y aire de algunos ambientes; Staphylotrichum, Gliocladium, Verticillium y Rhizopus, en las superficies, así como Chrysosporium, Stachybotrys, Cunninghamella, Alternaria, Cercospora y Nigrospora, en el aire (Tabla 3).

Las bacterias y los hongos identificados en los almacenes del museo Tumbas Reales Señor de Sipán, también han sido reportados como patógenos para el hombre, mencionándose Nocardia, como causante de endocarditis infecciosa y micetoma; Acinetobacter, responsable de infecciones nosocomiales multirresistentes; Bacillus y Streptococcus, causantes de trastornos diversos en niños; Aspergillus, Penicillium, Alternaria y los mucorales, como causantes de procesos alérgicos y Rhizopus, Aspergillus y Penicillium, asociados a infecciones oportunistas en personas inmunodeprimidas. La presencia de bacterias y de hongos filamentosos en los ambientes de almacenamiento del material histórico representa un riesgo potencial de biodeterioro y enfermedades para los curadores, requiriéndose implementar adecuadas medidas de control y de mantenimiento. Se aislaron Bacillus, Micrococcus, Acinetobacter, Nocardia, Streptococcus, Staphylococcus y Streptomyces y los géneros de hongos filamentosos: Aspergillus, Cladosporium, Circinella, Syncephalastrum, Penicillium, Alternaria, Staphylotrichum, Cercospora, Rhizopus, Cunninghamella, Chrysosporium, Nigrospora, Stachybotrys, Gliocladium y Verticillium, en los almacenes del museo Tumbas Reales de Sipán.
Agradecimientos. Al Museo Tumbas Reales, por habernos facilitado las muestras para el estudio y a Edgar Bracamonte Lévano, en la realización del estudio. Financiación: Autofinanciado. Conflictos de interés: El manuscrito fue preparado y revisado con la participación de todos los autores, quienes declaramos que no existe conflicto de intereses que ponga en riesgo la validez de los resultados presentados.

\section{REFERENCIAS}

1. BARNET'T, H.L.; HUNTER, B.B. 1998. Illustrated Genera of Imperfect Fungi. 4th Edition, APS Press, St. Paul. 218p.

2. CAVKA, M.; GLASNOVIĆ, A.; JANKOVIĆ, I.; SIKANJIĆ, P.R.; PERIĆ, B.; BRKLJACIĆ, B.; MLINARIĆ-MISSONI, E.; SKRLIN, J. 2010. Microbiological analysis of a mummy from the archeological museum in Zagreb. Collegium Antropologicum. 34(3):803-805.

3. CHMIEL, M.; KRAL, I.; LENART-BORON, A. 2019. Concentration and size distribution of microbial aerosol in the historical objects in Kraków as a potential health risk and biodeterioration factor. Aerobiologia. 35(4):743-758. https://doi.org/10.1007/s10453-019-09614-x

4. CIFERRI, O. 2002. The role of microorganisms in the degradation of cultural heritage. Studies in Conservation. 47(Supplement-1):35-45. https://doi.org/10.1179/sic.2002.47.supplement-1.35

5. COX, C.S.; WATHES, C.M. 1995. Bioaerosols handbook. crc press.

6. DAÂSSI, D.; ZOUARI-MECHICHI, H.; BELBAHRI, L.; BARRIUSO, J.; MARTÍNEZ, M.J.; NASRI, M.; MECHICHI, T. 2016. Phylogenetic and metabolic diversity of Tunisian forest wood-degrading fungi: a wealth of novelties and opportunities for biotechnology. 3 Biotech. 6(1):46.

https://doi.org/10.1007/s13205-015-0356-8

7. EYZAGUIRRE, M.P.L. 2002. Análisis científico de fibras arqueológicas. Conserva. 6(1):47-59.

8. FAROOQ, M.; HASSAN, M.; GULL, F. 2015. Mycobial Deterioration of Stone Monuments of Dharmarajika, Taxila. J. Microbiology \& Experimentation. 2(1):29-33. https://doi.org/10.15406/jmen.2015.02.00036

9. GRBIĆ, M.L.; STUPAR, M.; VUKOJEVIĆ, J.; MARIČIĆ, I.; BUNGUR, N. 2013. Molds in museum environments: Biodeterioration of art photographs and wooden sculptures. Archives of Biological Sciences. 65(3):955-962. https://doi.org/10.2298/ABS1303955G 
10. GU, J.D. 2003. Microbiological deterioration and degradation of synthetic polymeric materials: Recent research advances. Internal Biodeterioration and Biodegradation. 52(2):69-91. https://doi.org/10.1016/S0964-8305(02)00177-4

11. GU, J.D.; FORD, T.E.; BERKE, N.S.; MITCHELL, R. 1998. Biodeterioration of concrete by the fungus Fusarium. Internal Biodeterioration and Biodegradation. 41(2):101-109. https://doi.org/10.1016/S0964-8305(98)00034-1

12. GUIAMET, P.; BORREGO, S.; LAVIN, P.; PERDOMO, I.; GÓMEZ DE SARAVIA, S. 2011. Biofouling and biodeterioration in materials stored at the Historical Archive of the Museum of La Plata, Argentine and at the National Archive of the Republic of Cuba. Colloids and Surfaces B: Biointerfaces. 85(2):229-234.

https://doi.org/10.1016/j.colsurfb.2011.02.031

13. HÖRZ, G.; KALLFASS, M. 2000. The treasure of gold and silver artifacts from the Royal Tombs of Sipán, Peru - A study on the Moche metalworking techniques. Materials Characterization. 45(4-5):391-419.

https:/ /doi.org/10.1016/S1044-5803(00)00093-0

14. KAKAKHEL, M.A.; WU, F.; GU, J.D.; FENG, H.; SHAH, K.; WANG, W. 2019. Controlling biodeterioration of cultural heritage objects with biocides: A review. Internal Biodeterioration and Biodegradation. 143(2019):104721.

https://doi.org/10.1016/j.ibiod.2019.104721

15. KARBOWSKA-BERENT, J.; GÓRNY, R.L.; STRZELCZYK, A.B.; WLAZLO, A. 2011. Airborne and dust borne microorganisms in selected Polish libraries and archives. Building and Environment. 46(10):1872-1879.

https://doi.org/10.1016/j.buildenv.2011.03.007

16. KONSA, K.; TIRRUL, I.; HERMANN, A. 2014. Wooden objects in museums: Managing biodeterioration situation. Internal Biodeterioration and Biodegradation. 86(2014):165-170.

https://doi.org/10.1016/j.ibiod.2013.06.023

17. LABARCA, M.; SANABRIA, N.; ARCIA, A. 2006. Patogenicidad de Pestalotiopsis palmarum Cooke, sobre plantas de vivero de palma aceitera (Elaeis guineensis Jacq.). Rev. Fac. Agron. (LUZ). 23:417-424

18. LIU, X.; MENG, H.; WANG, Y.; KATAYAMA, Y.; GU, J.D. 2018. Water is a critical factor in evaluating and assessing microbial colonization and destruction of Angkor sandstone monuments. Internal Biodeterioration and Biodegradation. 133(2018):9-16.

https://doi.org/10.1016/j.ibiod.2018.05.011

19. LÓPEZ-ARANDA, B.G.; IGLESIAS-OSORES, S.; TULLUME GONZALES, L.; CARREÑO-FARFAN, C.
2020. Caracterización microbiológica de los almacenes del museo tumbas reales de Sipán en Lambayeque, Perú. La zaranda de ideas. 18(2):136-145.

20. MENG, H.; KATAYAMA, Y.; GU, J.D. 2017. More wide occurrence and dominance of ammonia-oxidizing archaea than bacteria at three Angkor sandstone temples of Bayon, Phnom Krom and Wat Athvea in Cambodia. Internal Biodeterioration and Biodegradation. 117:78-88. https://doi.org/10.1016/j.ibiod.2016.11.012

21. MENG, H.; LUO, L.; CHAN, H.W.; KATAYAMA, Y.; GU, J.D. 2016. Higher diversity and abundance of ammonia-oxidizing archaea than bacteria detected at the Bayon Temple of Angkor Thom in Cambodia. Internal Biodeterioration and Biodegradation. 115(2016):234-243. https://doi.org/10.1016/j.ibiod.2016.08.021

22. MONTANARI, M.; MELLONI, V.; PINZARI, F; INNOCENTI, G. 2012. Fungal biodeterioration of historical library materials stored in Compactus movable shelves. Internal Biodeterioration and Biodegradation. 75:83-88.

https://doi.org/10.1016/j.ibiod.2012.03.011

23. OBRUCA, S.; MAROVA, I.; MATOUSKOVA, P.; HARONIKOVA, A.; LICHNOVA, A. 2012. Production of lignocellulose-degrading enzymes employing Fusarium solani F-552. Folia Microbiologica. 57(3):221-227.

24. PIÑAR, G.; PIOMBINO-MASCALI, D.; MAIXNER, F.; ZINK, A.; STERFLINGER, K. 2013. Microbial survey of the mummies from the Capuchin Catacombs of Palermo, Italy: biodeterioration risk and contamination of the indoor air. FEMS Microbiology Ecology. 86(2):341-356. https://doi.org/10.1111/1574-6941.12165

25. ROJAS, T.I.; AIRA, M.J.; BATISTA, A.; CRUZ, I.L.; GONZÁLEZ, S. 2012. Fungal biodeterioration in historic buildings of Havana (Cuba). Grana. 51(1):44-51. https://doi.org/10.1080/00173134.2011.643920

26. SEQUEIRA, S.; CABRITA, E.J.; MACEDO, M.F. 2012. Antifungals on paper conservation: An overview. Internal Biodeterioration and Biodegradation. 74(2012):67-86. https://doi.org/10.1016/j.ibiod.2012.07.011

27. SHIMADA, I.; HÄUSLER, W.; JAKOB, M.; MONTENEGRO, J.; RIEDERER, J.; WAGNER, U. 2003. Early pottery making in Northern Coastal Peru. Part IV: Mössbauer study of ceramics from Huaca Sialupe. Hyperfine Interactions. 150(1-4):125-139. https://doi.org/10.1023/B:HYPE.0000007354.42840.ef

28. STERFLINGER, K.; PIÑAR, G. 2013. Microbial deterioration of cultural heritage and works of art - Tilting at windmills? 
Applied Microbiology and Biotechnology. 97(22):9637-9646. https://doi.org/10.1007/s00253-013-5283-1

29. WARSCHEID, T.; BRAAMS, J. 2000. Biodeterioration of stone: A review. Internal Biodeterioration and Biodegradation. 46(4):343-368.

https://doi.org/10.1016/S0964-8305(00)00109-8
30. ZHU, H.; PHELAN, P.E.; DUAN, T.; RAUPP, G.B.; FERNANDO, H.J.S.; CHE, F. 2003. Experimental study of indoor and outdoor airborne bacterial concentrations in Tempe, Arizona, USA. Aerobiologia. 19(3-4):201-211. https://doi.org/10.1023/B:AERO.0000006571.23160.8a 